\title{
Triethylamine induced synthesis of silver and bimetallic (Ag/Au) nanoparticles in glycerol and their antibacterial study
}

\author{
Pradnya Nalawade $\cdot$ Poulomi Mukherjee $\cdot$ \\ Sudhir Kapoor
}

Received: 24 March 2014 / Accepted: 6 June 2014/Published online: 25 June 2014

(C) The Author(s) 2014. This article is published with open access at Springerlink.com

\begin{abstract}
Formation of $\mathrm{Ag}$ nanoplates in the presence of glycerol/triethylamine/polyvinylpyrrolidone without using any external reducing agent is shown for the first time. This approach is a unique and size-controlled synthetic method for the preparation of Ag nanoplates. Results reveal that addition of triethylamine to the precursor reaction mixture plays an important role both as a reagent for initiation and accelerator to produce nanoparticles at room temperature in the presence of glycerol. The basicity of the reaction mixture results in the appearance of two strongly localized surface plasmon resonance peaks of Ag nanoplates, effectively indicating the steady transition from non-planar structure to planar structure as confirmed by UV-Vis and transmission electron microscope measurements. The antibacterial activity of $\mathrm{Ag}$ and bimetallic $(\mathrm{Ag} / \mathrm{Au})$ nanoparticles were tested against gram-negative and grampositive bacteria. The enhanced antibacterial activity was observed with bimetallic nanoparticles with equal concentration of silver.
\end{abstract}

Keywords Metals - Nanostructures - Optical properties · Chemical synthesis - Antibacterial activity

Electronic supplementary material The online version of this article (doi:10.1007/s40097-014-0113-2) contains supplementary material, which is available to authorized users.

P. Nalawade $\cdot$ S. Kapoor $(\bowtie)$

Radiation \& Photochemistry Division, Bhabha Atomic Research

Centre, Mumbai 400 085, India

e-mail:sudhirk@barc.gov.in

P. Mukherjee

Nuclear Agriculture \& Bio-technology Division, Bhabha Atomic Research Centre, Trombay, Mumbai 400 085, India

\section{Introduction}

Synthesis of noble metal nanoparticles are currently of significant interest because of their potential applications such as catalysis, surface-enhanced Raman scattering, photoelectronic devices, biomedical diagnostics, and other related fields [1-5]. Among the various noble metals, $\mathrm{Ag}, \mathrm{Au}$, and $\mathrm{Cu}$ nanoparticles have become the focus of intensive research because they exhibit unusual optical, electronic, and chemical properties, depending on their size and shape, thus opening many possibilities for technological applications such as antibacterial, antistatic, cryogenic superconducting or biosensor materials [1-5]. This led to a rapid increase in the number of scientific publications devoted to the development of the preparation techniques for the synthesis of these noble metals $[6,7]$.

$\mathrm{Ag}$ is known to have antibacterial activity against various pathogenic bacteria. Bacteria can build up resistance against antibiotic drugs, in contrast Ag nanoparticles attack various components in the bacterial cell by weakening of DNA replication and inactivation of proteins $[8,9]$. However, Au shows low or no toxicity to bacteria or animal due to its elemental properties [10]. It is surprising that the antibacterial efficacy of bimetallic core-shell nanoparticles containing Ag remains roughly unexplored and only a few studies are reported. In a recent study it is reported that in the presence of Ag the antibacterial activity of Au could be enhanced [11].

Polyols, especially ethylene glycol (EG) and glycerol, have been widely used as solvents and/or mild reductants in nanoparticles' synthesis [12-15]. Our previous work has demonstrated that $\mathrm{Ag}$ nanoparticles can be stabilized in ethylene glycol using ionizing radiation [12]. It is known that polyols undergo 
oxidation in basic conditions that help in reduction of metal ions [16, 17]. Recently, the effect of trietylamine (TEA) on the preformed Ag nanoparticles and during the formation of $\mathrm{Au}$ nanoparticles is discussed in literature [18-20]. Inspired by these works, in the present study a simple solvent-induced synthesis and characterisation of $\mathrm{Ag}, \mathrm{Au}$, and bimetallic $\mathrm{Ag}-\mathrm{Au}$ nanoparticles in neat or aqueous solution of glycerol has been described in detail. TEA a weak organic base was used to initiate the reaction. The effect of stabilizing agents such as polyvinylpyrrolidone (PVP) and sodium dodecyl sulfate (SDS) on the formation and stability of the particles is discussed. A series of characterizing techniques including transmission electron microscopy (TEM), UV-Vis, and X-ray diffraction (XRD) were performed systematically to determine the morphology of nanoparticles. In the present study, we have also investigated the antibacterial properties of bimetallic Au@Ag core-shell nanoparticles where Ag nanoparticles were formed on the surface of $\mathrm{Au}$ nanoparticles. The antibacterial activity was tested against the pathogenic gram-negative bacteria $E$. coli and gram-positive bacteria Staphylococcus sp.

\section{Experimental procedure}

\section{Materials}

Glycerol (Spectrochem, India), silver nitrate $\left(\mathrm{AgNO}_{3}\right)(\mathrm{S} . \mathrm{D}$ Fine Chem. India), TEA (Sigma), PVP (Mol. wt. 40,000) (Sigma), SDS (Sigma-Aldrich), and $\mathrm{HAuCl}_{4}$ (SigmaAldrich) were used as received. All the solutions were prepared just prior to the experiment to avoid any photochemical reaction. Water used in the preparations was obtained from a Millipore water purifying system. All experiments and the various sample preparations were carried out at room temperature.

\section{Synthesis of $\mathrm{Ag}$ and $\mathrm{Au}$ nanoparticles}

In a typical synthesis, $0.6 \mathrm{mM}$ aqueous solution of $\mathrm{AgNO}_{3}$ was mixed with $1.0 \mathrm{mM}$ TEA in required concentration of glycerol (in the range of $0-80 \% \mathrm{v} / \mathrm{v}$ ) in the absence and presence of stabilizing agent, PVP or SDS at room temperature. The influence of TEA was studied by adding it to the reaction mixtures after addition of all the reactants. Changes in the color of solutions indicate the formation of Ag nanoparticles. Formation of stable yellow dispersion was obtained with time. Au nanoparticles were prepared by mixing $\mathrm{Au}$ salt in required concentration of glycerol in aqueous solutions followed by the addition of TEA.
Synthesis of bimetallic Ag/Au nanoparticles

In 10-mL volumetric flask wine red colored $\mathrm{Au}$ seeds were first prepared by adding $\mathrm{Au}^{3+}$ ions to the $10 \%$ aqueous solution of glycerol containing TEA and SDS. To the above seed solution $0.6 \mathrm{mM} \mathrm{AgNO}_{3}$ was added followed by addition of $1.0 \mathrm{mM}$ TEA and $0.5 \mathrm{~mL}$ of glycerol. The final concentration of glycerol, TEA, SDS, and metal ion was $20 \%(\mathrm{v} / \mathrm{v}), 2.0,5.0$, and 6.0 respectively.

\section{Antibacterial activity}

Wild-type E. coli BW 25113 was grown in Luria Broth to an optical density of $0.1 .100 \mu \mathrm{L}$ of such culture was inoculated in $5 \mathrm{~mL}$ Luria broth suitably supplemented with various concentrations of bimetallic and $\mathrm{Ag}$ nanoparticles (3.2-38.8 $\mu \mathrm{g} / \mathrm{mL})$. Simultaneously, control tubes without nanoparticles but same amount of inoculums and without inoculums and nanoparticles were also run. The tubes were incubated overnight in an orbital shaker at $37^{\circ} \mathrm{C}$ at $150 \mathrm{rpm}$. Next morning the tubes were inspected for visual presence of turbidity, indicative of bacterial growth. The lowest concentration of the inhibitory agent which did not give any turbidity upon overnight incubation was termed as the minimum inhibitory concentration (MIC). Similarly, $10^{5}-10^{6}$ colony-forming units (CFU) per $\mathrm{mL}$ of grampositive bacteria Staphylococcus sp. in Luria broth were also used to check for inhibitory effects of bimetallic nanoparticles.

\section{Characterization}

UV-Vis absorption measurements were performed on JASCO V-650 spectrophotometer. Particle size estimation, transmission electron micrographs, and electron diffraction patterns were recorded on a JEOL 2000 FX machine operated at $200 \mathrm{keV}$. Samples for transmission electron microscopy (TEM) were prepared by putting a drop of the colloidal solution on a copper grid coated with a thin amorphous carbon film placed on a filter paper. Powder X-ray diffractions (PXRDs) were measured on precipitated nanoparticles using Philips X'pert Pro machine with monochromatised $\mathrm{Cu} \mathrm{K} \alpha \mathrm{X}$-ray source operated at $20 \mathrm{kV}$ and $30 \mathrm{~mA}$. Dynamic light scattering experiments were done on a Malvern 4800 Autosizer employing a 7132 digital correlator. The intensity correlation function was analyzed by the method of cumulants using the mean and variance of the distribution as the fitted variable. The diffusion coefficient $(D)$ of the particle is related to the average decay rate $(\Gamma)$ of the correlation function by $\Gamma=D q^{2}$, where $q$ is the magnitude of the scattering vector (given by $q n=42 \pi \lambda \theta \sin /$, where $\lambda$ is the wavelength of 
light, $n$ is the refractive index, and $\theta$ is the scattering angle). The mean hydrodynamic coefficient of the particles was obtained from the diffusion coefficient using StokesEinstien relationship. The light source was an $\mathrm{Ar}^{+}$ion laser operated at $514.5 \mathrm{~nm}$ and scattering angle $\theta=90^{\circ}$.

\section{Results and discussion}

\section{Synthesis of Ag nanoparticles}

Figure 1a shows the UV-Vis spectra of Ag nanoparticles obtained in the presence of $0.6 \mathrm{mM} \mathrm{AgNO}^{3}$ and $1.0 \mathrm{mM}$ of TEA with different compositions of glycerol:water $(0-40 \% \mathrm{v} / \mathrm{v})$ in the absence of any stabilizer. The higher percentage of glycerol $(>40 \%)$ was not attempted as mixing of the reactants was not homogeneous due to increase in the viscosity of the solution. It can be seen that the peak maximum was centered in the wavelength region of $400-440 \mathrm{~nm}$. The color of the Ag solution was seen to have changed to greenish yellow orange shades. The change in colors and characteristic surface plasmon absorption spectra indicate the formation of Ag nanoparticles [21-23]. The observed surface plasmon absorption band appears to be broader with an asymmetric shape at all the compositions of glycerol:water. The shoulder at $580 \mathrm{~nm}$ in case of $20 \%$ glycerol and broadening of absorption band at higher wavelength might be attributed to the formation of nanoparticles with different geometry or may be due to small aggregation of primary particles, because with time nanoparticles were precipitated out from the reaction mixture. This can be further evident from the transmission electron microscopy (TEM) analysis. Figure $1 \mathrm{~b}$ shows the TEM image of Ag nanoparticles obtained in the presence of $0.6 \mathrm{mM} \mathrm{AgNO}_{3}, 1 \mathrm{mM}$ TEA in the presence of $20 \%$ of glycerol in water. TEM analysis shows that particles were polydispersed with few aggregates; the average particle size is $30 \mathrm{~nm}$.

It can be seen from Fig. 1 that the absorbance yield increased in the presence of glycerol. The increased absorbance may be correlated to the production of metal nanoparticles in larger quantities in the presence of glycerol. It is important to mention here that in the absence of TEA no formation of $\mathrm{Ag}$ nanoparticles was observed. It was observed that on addition TEA, the reduction rate of $\mathrm{Ag}^{+}$ions increased resulting in the simultaneous increase in nucleation and growth rate of $\mathrm{Ag}$ particles. This confirms the participation of TEA in acceleration of reduction reaction.

Since, in absence of stabilizing agent, particles tend to aggregate, efforts have been made to make Ag nanoparticles in the presence of stabilizing agents like SDS and PVP. Figure 2 shows the UV-Vis surface plasmon absorption spectra of Ag nanoparticles obtained in the solutions after mixing of $\mathrm{Ag}^{+}$ions with $20 \%$ glycerol at different $\left[\mathrm{Ag}^{+}\right] /$ [SDS] ratios. Visually, instant change in colors of the mixed solutions could be seen clearly. The color of the Ag solution was seen to have changed to yellow orange shades as shown in the inset of Fig. 2. Both, the change in colors and characteristic absorption spectra indicated the formation of $\mathrm{Ag}$ nanoparticles. The plasmon peaks of $\mathrm{Ag}$ nanoparticles increased in intensity and the $\lambda_{\max }$ gradually shifted towards higher wavelengths with the increasing relative concentration of $\mathrm{Ag}$ salt as shown in inset of Fig. 2. This might be due to the formation of large size nanoparticles at higher concentrations of $\mathrm{Ag}$ salt. Thus, variation in size of the particles with $\left[\mathrm{Ag}^{+}\right]$keeping the amount of SDS constant was determined by DLS measurement (Table 1). It can be noted that as the concentration of $\mathrm{Ag}^{+}$ions increased the size of the particles also increased. The formation of $\mathrm{Ag}$ nanoparticles was instant with no induction time for the reaction (inset Fig. 2).

It was found that no particle formation occurred when the concentration of TEA was below $1.0 \mathrm{mM}$. TEM images have shown that when the concentration SDS was below $5.0 \mathrm{mM}$, large aggregates with average diameter of $75 \mathrm{~nm}$ were formed (results not shown). However, monodispersed Ag nanoparticles were obtained when the concentration of SDS was $\geq 5.0 \mathrm{mM}$ which highlights the role of SDS in formation and stabilization of $\mathrm{Ag}$ nanoparticles (Fig. 2). It
Fig. 1 a UV-Vis spectra of Ag nanoparticles prepared with different composition of glycerol:water mixture containing $0.6 \mathrm{mM} \mathrm{AgNO}_{3}$ in the presence of $1 \mathrm{mM}$ TEA. Path length of cell $1 \mathrm{~cm}$. b TEM image of $\mathrm{Ag}$ nanoparticles. c Corresponding electron diffraction pattern
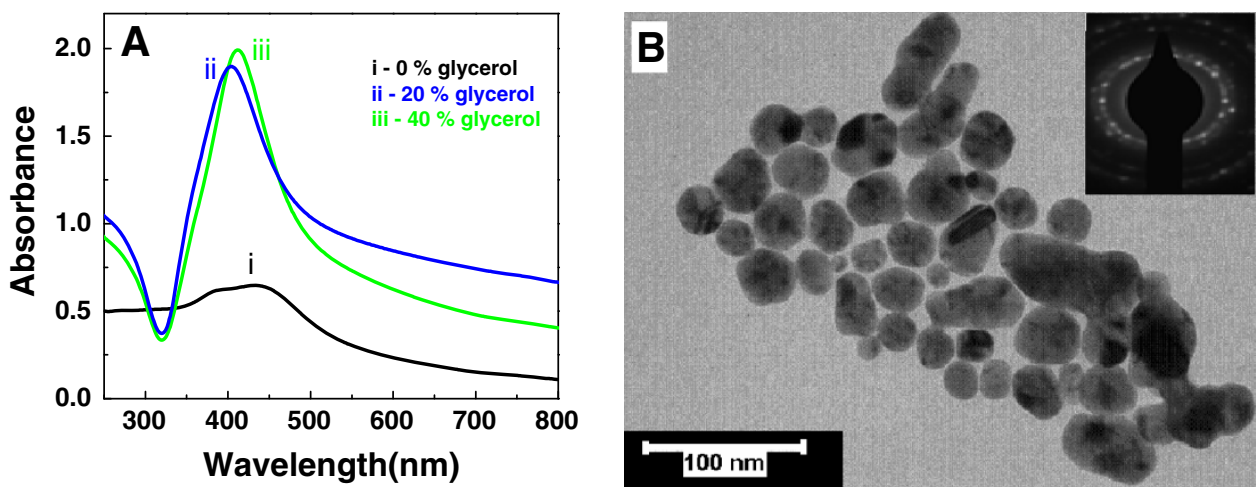


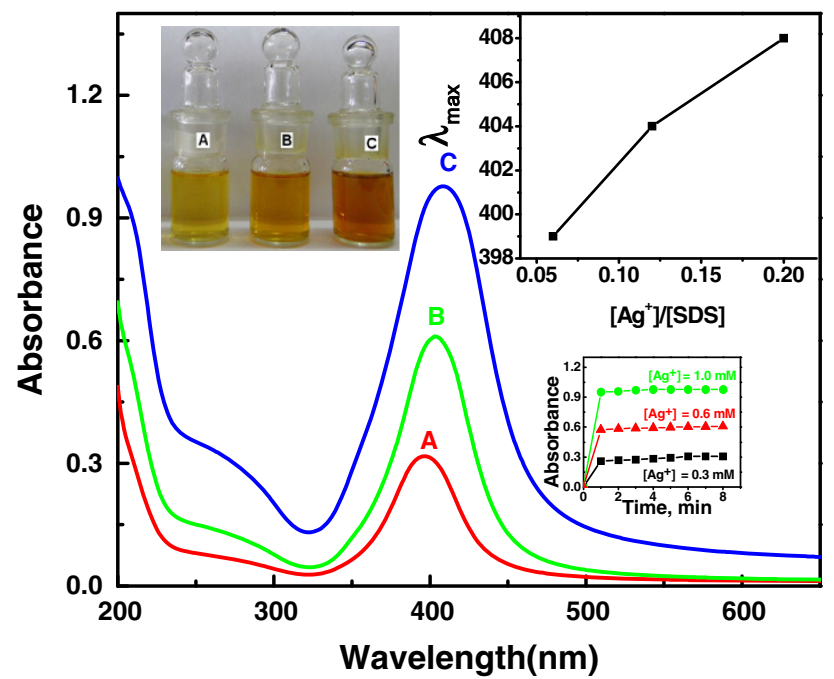

Fig. 2 UV-Vis spectra of Ag nanoparticles prepared in $20 \%$ glycerol in the presence of $1 \mathrm{mM}$ TEA with different $\left[\mathrm{Ag}^{+}\right] /[\mathrm{SDS}]$ ratios. Path length of cell $0.22 \mathrm{~cm}$. Insets photographs of $\mathrm{Ag}$ nanoparticles, variation in the absorption maximum and kinetic traces for the formation of $\mathrm{Ag}$ nanoparticles prepared with different $\left[\mathrm{Ag}^{+}\right] /[\mathrm{SDS}]$ ratios, $(A) 0.06,(B) 0.12,(C) 0.2$ in the presence of $5 \mathrm{mM}$ SDS and $1 \mathrm{mM}$ TEA

Table 1 Particle size variation with $\mathrm{Ag}$ ion concentration

\begin{tabular}{ll}
\hline $\begin{array}{l}\left.\mathrm{Ag}^{+}\right], \\
\mathrm{mM}\end{array}$ & $\begin{array}{l}\text { Particle diameter } \\
(\mathrm{nm})\end{array}$ \\
\hline 0.3 & 18 \\
0.6 & 20 \\
1.0 & 24 \\
\hline
\end{tabular}

can be seen that the formed particles are spherical in nature having the average diameter $20 \pm 5 \mathrm{~nm}$ with a size distribution, ranging from 15 to $25 \mathrm{~nm}$ which is in agreement with DLS studies (Fig. S1).

To study the effect of stabilizer, if any, the above experiments were carried out in the presence of PVP. Figure 3 shows the time-dependent UV-Vis absorption spectra of a Ag colloid in $20 \%$ glycerol solution containing $0.6 \mathrm{mM} \mathrm{AgNO}_{3}$ in the presence of $1.0 \mathrm{mM}$ TEA and $1 \%$ PVP. The peak maximum centered at $405 \mathrm{~nm}$ corresponds to the surface plasmon resonance due to the presence of spherical Ag nanoparticles, along with the presence of shoulder at $531 \mathrm{~nm}$ which gradually red shifted with increasing absorption and finally formed a distinct peak at $600 \mathrm{~nm}$. This new peak at longer wavelength is characteristic of formation of anisotropic nanoparticles having geometry other than spherical [1]. However, at lower concentration of $\mathrm{Ag}$ ions $(0.1 \mathrm{mM})$ such spectral changes were not seen.

The above observations were further evident from the TEM analysis. Figure 4 shows TEM image of particles

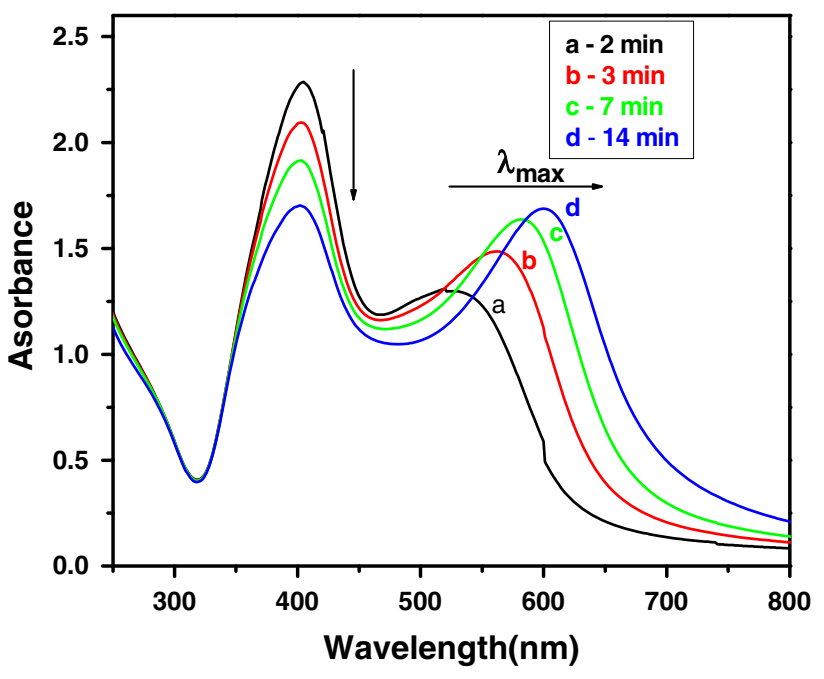

Fig. 3 Time-dependent UV-visible spectra of $\mathrm{Ag}$ particles in aqueous solution of $20 \%(\mathrm{v} / \mathrm{v})$ glycerol and $1 \mathrm{mM}$ TEA in the presence of $1 \% \operatorname{PVP}(\mathrm{w} / \mathrm{v})$

formed by reduction of 0.1 and $0.6 \mathrm{mM}$ of $\mathrm{Ag}$ ions, respectively, in the presence of $1 \%$ PVP (w/v). Spherical nanoparticles of average diameter of $25 \mathrm{~nm}$ were obtained at low $\left[\mathrm{Ag}^{+}\right]$concentration; however, in the presence of high concentration of $\mathrm{Ag}$ ions $(\geq 0.3 \mathrm{mM})$ in addition to spherical particles, anisotropic nanoparticles having irregular shapes and few percentage of definite geometric shapes are also obtained. The observed particles were stable for at least 1 month. The observed absorption bands in the surface plasmon spectrum might be due to the dual role of PVP in the above system, i.e., it acts as a stabilizing agent to prevent aggregation of $\mathrm{Ag}$ nanoparticles for retaining their colloidal stability. In addition, it also works as a shape-controlling agent or "a crystal-habit modifier", directing the attachment of metal atoms onto the specific crystal faces which leads to the highly anisotropic growth of nuclei into nanostructure [24, 25]. Xia et al. [26-28] also have demonstrated that the commercially available PVP terminated with hydroxyl end groups and works both as a reducing agent and stabilizer for the synthesis of $\mathrm{Ag}$ nanoplates.

The crystal structure of the Ag nanoparticles with and without the presence of stabilizers in $20 \%$ glycerol was examined by PXRD (Fig. 5). The diffraction peaks at $2 \theta=38.5^{\circ}, 45^{\circ}$, and $65^{\circ}$ can be indexed to the (111), (200), and (220) planes of face-centered cubic Ag, respectively (JCPDS No. 04-0783). The average particle size of Ag nanoparticles in the presence of PVP, SDS, and without stabilizer was calculated by the Scherrer equation $D=k \lambda / \beta \cos \theta$,

where $\lambda$ is the $\mathrm{X}$-ray wavelength $(0.154056 \mathrm{~nm}), k=0.89$, $\beta$ is the FWHM, and $\theta$ is the diffraction angle. The 

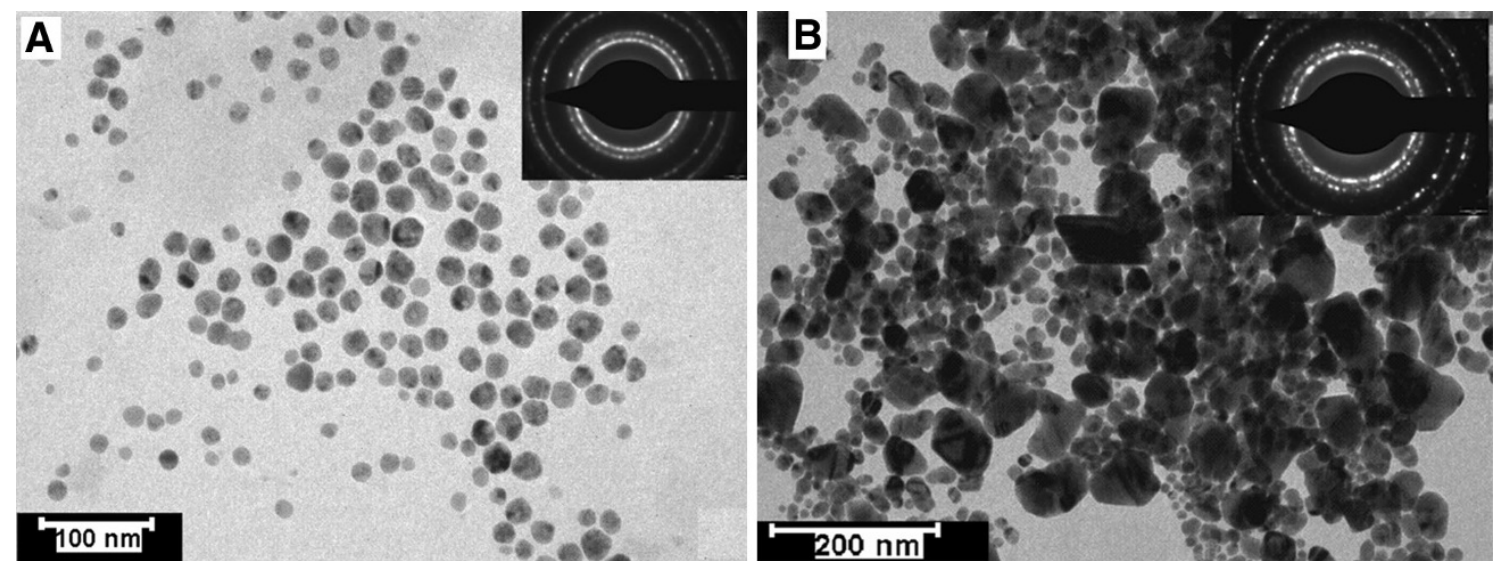

Fig. 4 Transmission electron micrograph of Ag nanoparticles in $20 \%$ glycerol a for $0.1 \mathrm{mM}, \mathbf{b} 0.6 \mathrm{mM} \mathrm{Ag}$ ion concentration containing $1 \%$ PVP and $1 \mathrm{mM}$ TEA

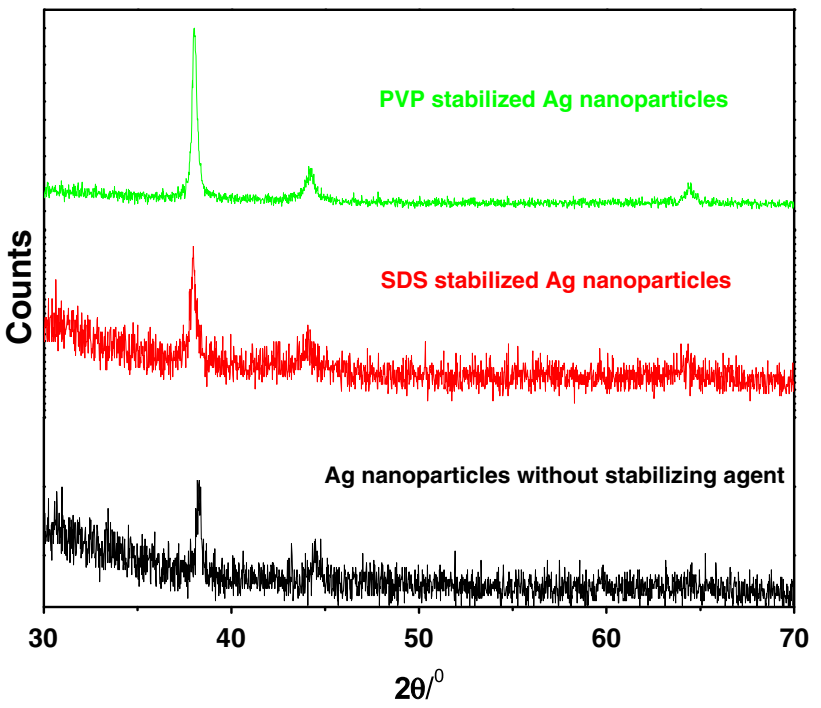

Fig. 5 XRD pattern of $\mathrm{Ag}$ nanoparticles prepared using different stabilizing agent

crystalline sizes calculated using the half-width of the intense (111) reflections were found to be 35,25 , and $20 \mathrm{~nm}$ for Ag nanoparticles prepared without stabilizing agent, with SDS and with PVP, respectively.

Taking into account literature reports [17-20] two possible mechanisms are proposed for the formation of $\mathrm{Ag}$ nanoparticles in glycerol in the presence of TEA. In mechanism 1 (Scheme 1), TEA oxidizes to diethylamine and acetaldehyde. Subsequently, the generated diethylamine and acetaldehyde further oxidized in presence of $\mathrm{Ag}^{+}$ions to give ethylamine and acetic acid, respectively, with concomitant formation of $\mathrm{Ag}$ nanoparticles. In the other plausible path (mechanism 2) glycerol dehydrates to aldehyde which subsequently gets oxidized to acid in the presence of $\mathrm{Ag}^{+}$ions. The above-mentioned mechanisms may occur concurrently.
Mechanism 1
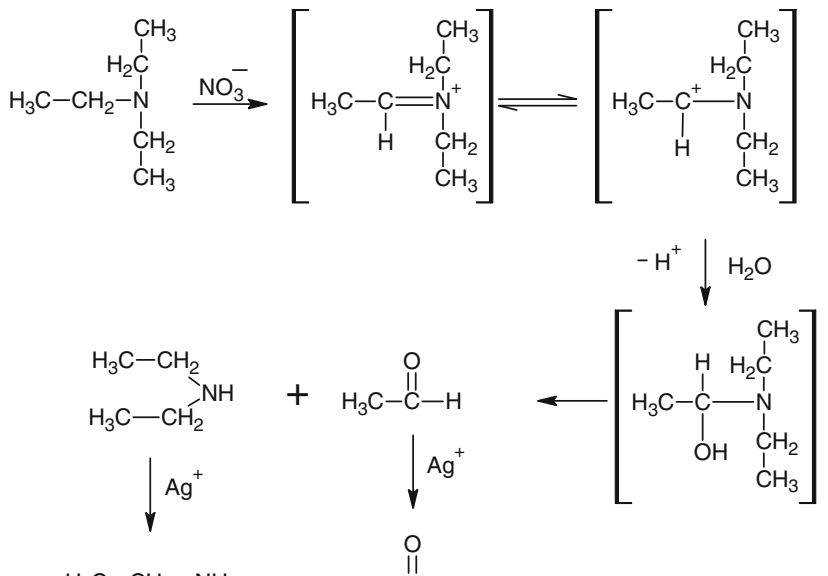

$\mathrm{H}_{3} \mathrm{C}-\mathrm{CH}_{2}-\mathrm{NH}_{2}$ $\mathrm{H}_{3} \mathrm{C}-\mathrm{C}-\mathrm{OH}$<smiles>CC(CC(C)(C)C)C(C=O)C(CO)CO</smiles>

Scheme 1 Proposed mechanisms for the formation of $\mathrm{Ag}$ nanoparticles

Synthesis of bimetallic nanoparticles

It is known that bimetallic nanoparticles containing two kinds of metals show unique electronic, optical, chemical, and catalytic properties [29-31]. Most of these properties are superior to their constituent monometallic nanoparticles due to synergistic effects. Generally, the bimetallic nanoparticles are formed as alloys and core-shell structures. In bimetallic core-shell nanoparticles one metal element forms an inner core and is surrounded by a concentric shell 

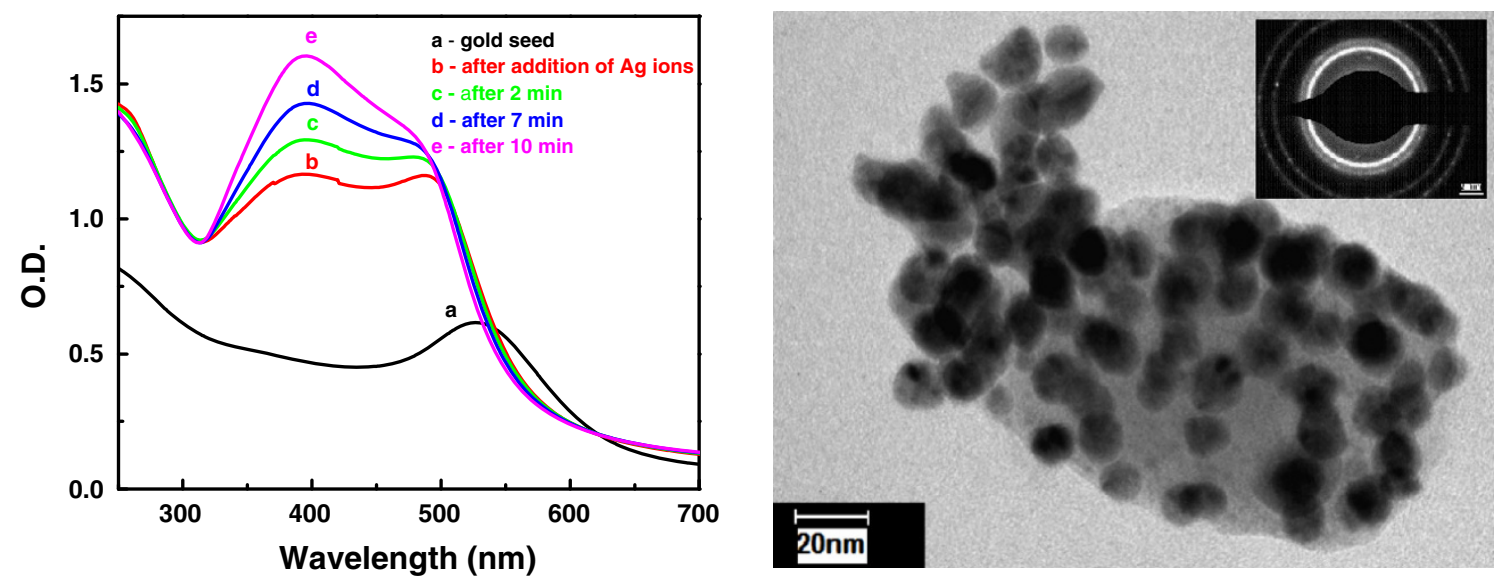

Fig. 6 UV-visible spectra and TEM image for the formation of Ag-Au bimetallic nanoparticles prepared in $20 \%$ glycerol and in the presence of equimolar ratio of $\mathrm{Ag}$ and $\mathrm{Au}$ ions (total molar concentration of both ions was $1.2 \mathrm{mM}$ ) with $5 \mathrm{mM}$ SDS and $1 \mathrm{mM}$ TEA

of another metal. As lattice parameters of $\mathrm{Au}$ and $\mathrm{Ag}$ are more or less similar it is easier to make alloy or core-shell nanoparticles of $\mathrm{Au}$ and $\mathrm{Ag}$.

Bimetallic core-shell $\mathrm{Ag}$ and $\mathrm{Au}$ nanoparticles were prepared using step-by-step reduction method. Au seeds were first prepared followed by reduction of $\mathrm{Ag}^{+}$ions on the surface of the Au seeds; the reaction was monitored as a function of time by UV-Vis spectroscopy measurements and the spectra obtained are shown in Fig. 6.

The peak centered at $525 \mathrm{~nm}$ is due to surface plasmon resonance of $\mathrm{Au}$ nanoparticles. The TEM image of $\mathrm{Au}$ nanoparticles is shown in Fig. S2. As soon as the $\mathrm{Ag}^{+}$ions are added to Au seeds, this peak gradually shifts to shorter wavelength with time along with the development of new peak at $405 \mathrm{~nm}$. This new peak in the wavelength region of $\sim 400 \mathrm{~nm}$ corresponds to the surface plasmon resonance of Ag nanoparticles; therefore, the blue shift in the absorption spectrum can be correlated to the reduction and deposition of $\mathrm{Ag}$ atoms on the surface of the Au nanoparticles which leads to the increase in the thickness of the Ag layer [3234]. However, we could not observe the single peak in the absorption band when $\mathrm{Ag}$ and $\mathrm{Au}$ ions were in equimolar concentration, i.e. 1:1, which indicates the partial coverage of Au by Ag nanoparticles. TEM analysis (Fig. 6) shows difference in contrast of nanoparticles. It can be seen that the formed particles are of spherical shape with average diameter of $13 \mathrm{~nm}$. Gonzalez et al. [35] also reported such layer-by-layer formation of core-shell $(\mathrm{Au}-\mathrm{Ag})$ nanoparticles by photochemical method.

\section{Antibacterial assay}

Figure 7 shows the photograph of culture tubes containing different concentrations of bimetallic nanoparticles $(3.2-38.8 \mu \mathrm{g} / \mathrm{mL})$ along with the media control and culture control. The concentration of bimetallic nanoparticles is

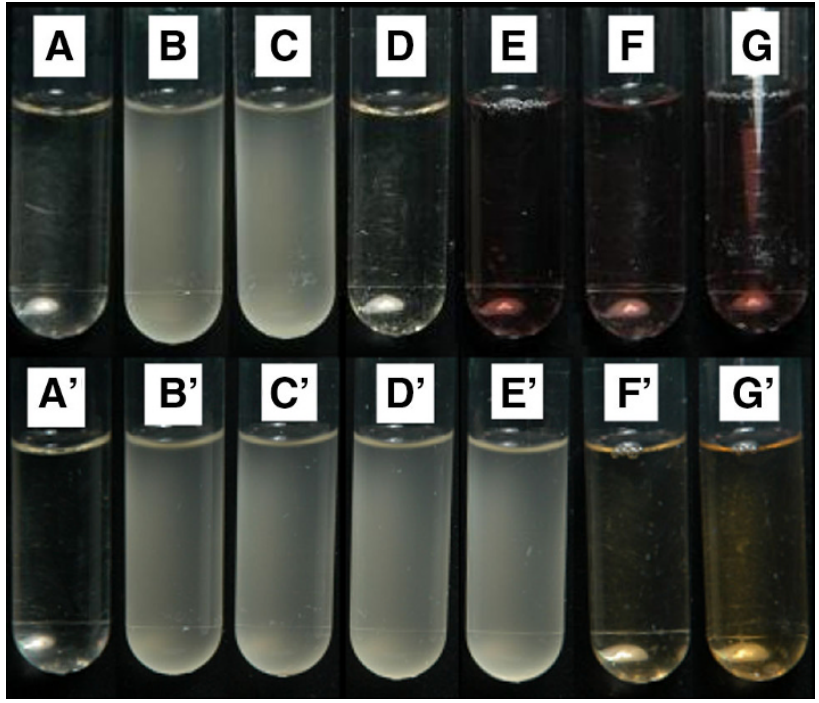

Fig. 7 Photograph of culture tubes containing different concentrations of bimetallic nanoparticles $(A)$ media control, $(B)$ culture control, (C) $3.2 \mu \mathrm{g} / \mathrm{ml},(D) 6.4 \mu \mathrm{g} / \mathrm{ml},(E) 12.9 \mu \mathrm{g} / \mathrm{ml},(F) 25.9 \mu \mathrm{g} /$ $\mathrm{ml},(G) 38.8 \mu \mathrm{g} / \mathrm{ml}$. And Ag nanoparticles $\left(A^{\prime}\right)$ media control, $\left(B^{\prime}\right)$ culture control, $\left(C^{\prime}\right) 3.2 \mu \mathrm{g} / \mathrm{ml},\left(D^{\prime}\right) 6.4 \mu \mathrm{g} / \mathrm{ml},\left(E^{\prime}\right) 12.9 \mu \mathrm{g} / \mathrm{ml},\left(F^{\prime}\right)$ $25.9 \mu \mathrm{g} / \mathrm{ml},\left(G^{\prime}\right) 38.8 \mu \mathrm{g} / \mathrm{ml}$

taken in terms of $\mathrm{Ag}$ ions as the antibacterial action of core-shell type of nanoparticles is only because of $\mathrm{Ag}$ shell. As can be seen from the photograph only the tube containing culture control (B) and $3.2 \mu \mathrm{g} / \mathrm{mL}$ of bimetallic nanoparticles (C) shows turbidity. Therefore, it can be concluded that the minimum inhibitory concentration (MIC) was obtained at $6.4 \mu \mathrm{g} / \mathrm{mL}$ of the inhibitory agent (bimetallic nanoparticles). The MIC for Ag nanoparticles was obtained at $25.9 \mu \mathrm{g} / \mathrm{mL}$, indicating the higher efficacy of the bimetallic nanoparticles in inhibiting bacterial growth. The enhanced antibacterial activity of $\mathrm{Au} @ \mathrm{Ag}$ 
core-shell nanoparticles as compared to monometallic $\mathrm{Ag}$ nanoparticles of somewhat similar sizes could be due to highly active surface $\mathrm{Ag}$ atoms in the shell around the $\mathrm{Au}$ core in core-shell nanoparticles. It has been established that the bactericidal action relies on the toxic effect of free $\operatorname{Ag}(\mathrm{I})$ ions liberated by oxidation with dissolved oxygen [36-38]. As the Au is more electronegative than Ag, it can withdraw electrons from the $\mathrm{Ag}$ shell. Hence, the high activity of $\mathrm{Ag}$ nanoparticles in the shell of bimetallic nanoparticles could also be due to electronic effects by $\mathrm{Au}$ nanoparticles/atoms in the core on surface Ag nanoparticles/atoms by charge transfer [11]. Thus, it can be concluded that the superior antibacterial activity of $\mathrm{Au} @ \mathrm{Ag}$ core-shell nanoparticles could be due to highly active surface Ag atoms in the shell and/or due to electronic effect in bimetallic nanoparticles.

Gram-positive bacteria Staphylococcus sp. was inhibited at a concentration of $25.9 \mu \mathrm{g} / \mathrm{mL}$. The concentration of bimetallic nanoparticles required to inhibit the growth of gram-positive bacteria is high which might be due to the well-known fact that the antibacterial action of Ag nanoparticles is by way of cleaving of the cell wall. This process is more effective in gram-negative bacterial wall due to their thin cell wall as compared to thick peptidoglycan layer of gram-positive bacteria [39]. It is pertinent to mention here that Au nanoparticles did not show inhibition against any type of bacteria.

\section{Conclusions}

In the present case, UV-visible spectroscopy and TEM clearly demonstrate that the simple addition of TEA in the presence of PVP gradually tunes the shape of the particles. Ag nanoplates or nanospheroidal structures were generated in solution mixture of $\mathrm{H}_{2} \mathrm{O}$ :glycerol containing TEA and $\mathrm{AgNO}_{3}$ at room temperature. TEA acts as a reductant in the reaction mixture. The strategy was also exploited to generate bimetallic particles. The antibacterial activity of the formed $\mathrm{Ag}$ and bimetallic nanoparticles against $E$. coli and Staphylococcus sp. bacteria is also studied. Bimetallic nanoparticles are found to show enhanced antibacterial activity against $E$. coli bacteria as compared to Ag nanoparticles of same concentration.

Acknowledgments The authors are grateful to Dr. B. N. Jagatap, Director, Chemistry Group, and Dr. D.K. Palit, Head, Radiation \& Photochemistry Division for their encouragement during the course of this study.

Open Access This article is distributed under the terms of the Creative Commons Attribution License which permits any use, distribution, and reproduction in any medium, provided the original author(s) and the source are credited.

\section{References}

1. Jin, R., Cao, Y., Mirkin, C.A., Kelly, K.L., Schatz, G.C., Zheng, J.G.: Photoinduced conversion of silver nanospheres to nanoprisms. Science 294, 1901-1903 (2001)

2. Astruc, D., Lu, F., Aranzaes, J.R.: Nanoparticles as recyclable catalysts: the frontier between homogeneous and heterogeneous catalysis. Angew. Chem. Int. Ed. 44, 7852-7872 (2005)

3. Seferos, D.S., Giljohann, D.A., Hill, H.D., Prigodich, A.E., Mirkin, C.A.: Nano-flares: probes for transfection and mRNA detection in living cells. J. Am. Chem. Soc. 129, 15477-15479 (2007)

4. Skrabalak, S.E., Chen, J., Au, L., Lu, X., Li, X., Xia, Y.: Gold nanocages for biomedical applications. Adv. Mater. 19, 3177-3184 (2007)

5. Daniel, M.-C., Astruc, D.: Gold nanoparticles: assembly, supramolecular chemistry, quantum-size-related properties, and applications toward biology, catalysis, and nanotechnology. Chem. Rev. 104, 293-346 (2004)

6. Kim, D., Jeong, S., Moon, J.: Synthesis of silver nanoparticles using the polyol process and the influence of precursor injection. Nanotechnology 17, 4019-4024 (2006)

7. Lee, K.J., Jun, B.H., Lee, Y.I., Joung, J.: Direct synthesis and inkjetting of silver nanocrystals toward printed electronics. Nanotechnology 17, 2424-2428 (2006)

8. Vertelov, G.K., Krutyakov, Y.A., Efremenkova, O.V., Olenin, A.Y., Lisichkin, G.V.: A versatile synthesis of highly bactericidal Myramistin stabilized silver nanoparticles nanotechnology 19, 357707-357713 (2008)

9. Feng, Q.L., Wu, J., Chen, G.Q., Cui, F.Z., Kim, T.N., Kim, J.O.: A mechanistic study of the antibacterial effect of silver ions on Escherichia coli and Staphylococcus aureus. J. Biomed. Mater. Res. 52, 662-668 (2000)

10. Jin, Y., Zhao, X.: Cytotoxicity of photoactive nanoparticles. In: Webster, T. (ed.) Safety of nanoparticles: from manufacturing to medical applications, pp. 19-31. Springer Science + Business Media, New York (2008)

11. Banerjee, M., Sharma, S., Chattopadhyay, A., Ghosh, S.S.: Enhanced antibacterial activity of bimetallic gold-silver coreshell nanoparticles at low silver concentration. Nanoscale $\mathbf{3}$, 5120-5125 (2011)

12. Jacob, J., Kapoor, S., Biswas, N., Mukherjee, T.: Size tunable synthesis of silver nanoparticles in water-ethylene glycol mixtures. Coll. Surf. A Physicochem. Eng. Asp. 301, 329-334 (2007)

13. Patel, K., Kapoor, S., Dave, D.P., Mukherjee, T.: Synthesis of Pt, $\mathrm{Pd} \mathrm{Pt} / \mathrm{Ag}$, and $\mathrm{Pd} / \mathrm{Ag}$ nanoparticles by microwave-polyol method. J. Chem. Sci. 117, 311-316 (2005)

14. Patel, K., Kapoor, S., Dave, D.P., Mukherjee, T.: Synthesis of Au, $\mathrm{Au} / \mathrm{Ag}, \mathrm{Au} / \mathrm{Pt}$ and $\mathrm{Au} / \mathrm{Pd}$ nanoparticles using the microwavepolyol method. Res. Chem. Intermed 32, 103-113 (2006)

15. Nalawade, P., Mukherjee, T., Kapoor, S.: Green synthesis of gold nanoparticles using glycerol as a reducing agent. Adv. Nanoparticles 2, 78-86 (2013)

16. Fievet, F., Lagier, J.P., Blin, B., Beaudoin, B., Figlarz, M.: Homogeneous and heterogeneous nucleations in the polyol process for the preparation of micron and submicron size metal particles. Solid State Ion 32, 198-205 (1989)

17. Chen, Li-J, Wan, C.-C., Wang, Y.-Y.: Chemical preparation of $\mathrm{Pd}$ nanoparticles in room temperature ethylene glycol system and its application to electroless copper deposition. J. Coll. Interface Sci. 297, 143-150 (2006)

18. Filippo, E., Serra, A., Buccolieri, A., Manno, D.: Controlled synthesis and chain-like self-assembly of silver nanoparticles through tertiary amine. Coll. Surf. A Physicochem. Eng. Asp. 417, 10-17 (2013) 
19. Filippo, E., Manno, D., Buccolieri, A., Serra, A.: Green synthesis of sucralose-capped silver nanoparticles for fast colorimetric triethylamine detection. Sens. Actuators B 178, 1-9 (2013)

20. Kuo, P.-L., Chen, C.-C.: Generation of gold thread from $\mathrm{Au}(\mathrm{III})$ and triethylamine. Langmuir 22, 7902-7906 (2006)

21. Henglein, A.: Small-particle research: physicochemical properties of extremely small colloidal metal and semiconductor particles. Chem. Rev. 89, 1861-1873 (1989)

22. Belloni, J.: Contribution of radiation chemistry to the study of metal clusters. Radiat. Res. 150, S9-S20 (1998)

23. Kapoor, S.: Preparation, characterization, and surface modification of silver Particles. Langmuir 14, 1021-1025 (1998)

24. Kan, C.X., Zhu, X.G., Wang, G.H.: Single-crystalline gold microplates: synthesis, characterization, and thermal stability. J. Phys. Chem. B 110, 4651-4656 (2006)

25. Tsuji, M., Hashimoto, M., Nishizawa, Y., Kubokawa, M., Tsuji, T.: Microwave-assisted synthesis of metallic nanostructures in solution. Chem. Eur. J. 11, 440-452 (2005)

26. Lim, B., Camargo, P.H.C., Xia, Y.: Mechanistic study of the synthesis of $\mathrm{Au}$ nanotadpoles, nanokites and microplates by reducing aqueous $\mathrm{HAuCl}_{4}$ with poly(vinylpyrrolidone). Langmuir 24, 10437-10442 (2008)

27. Washio, I., Xiong, Y., Yin, Y., Xia, Y.: Reduction by the end groups of poly(vinylpyrrolidone): a new and versatile route to the kinetically controlled synthesis of Ag triangular nanoplates. Adv. Mater. 18, 1745-1749 (2006)

28. Xiong, Y., Washio, I., Chen, J., Cai, H., Li, Z.Y., Xia, Y.: Poly(vinyl pyrrolidone): a dual functional reductant and stabilizer for the facile synthesis of noble metal nanoplates in aqueous solutions. Langmuir 22, 8563-8570 (2006)

29. Garcia-Gutierrez, D.I., Gutierrez-Wing, C.E., Giovanetti, L., Ramallo-Lopez, J.M., Requejo, F.G., Jose-Yacaman, M.: Temperature effect on the synthesis of $\mathrm{Au}-\mathrm{Pt}$ bimetallic nanoparticles. J. Phys. Chem. B 109, 3813-3821 (2005)
30. Ferrer, D., Torres-Castro, A., Gao, X., Sepulveda-Guzman, S., Ortiz-Mendez, U., Jose-Yacaman, M.: Three-layer core/shell structure in $\mathrm{Au}-\mathrm{Pd}$ bimetallic nanoparticles. Nano Lett. 7, 1701-1705 (2007)

31. Kariuki, N.N., Luo, J., Maye, M.M., Hassan, S.A., Menard, T., Naslund, H.R., Lin, Y., Wang, C., Engelhard, M.H., Zhong, C.-J.: Composition-controlled synthesis of bimetallic gold-silver nanoparticles. Langmuir 20, 11240-11246 (2004)

32. Mulvaney, P.: Surface plasmon spectroscopy of nanosized metal particles. Langmuir 12, 788-800 (1996)

33. Wang, X., Zhang, Z., Hartland, G.V.: Electronic dephasing in bimetallic gold-silver nanoparticles examined by single particle spectroscopy. J. Phys. Chem. B 109, 20324-20330 (2005)

34. Wang, H., Brandl, D.W., Nordlander, P., Halas, N.J.: Plasmon nanostructures: artificial molecules. Acc. Chem. Res. 40, 53-62 (2007)

35. Gonzalez, C.M., Liu, Y., Scaiano, J.C.: Photochemical strategies for the facile synthesis of gold-silver alloy and core-shell bimetallic nanoparticles. J. Phys. Chem. C 113, 11861-11867 (2009)

36. Beer, C., Foldbjerg, R., Hayashi, Y., Sutherland, D., Autrup, H.: Toxicity of silver nanoparticles-nanoparticle or silver ion? Toxicol. Lett. 208, 286-292 (2012)

37. Liu, J., Sonshine, D.A., Shervani, S., Hurt, R.H.: Controlled release of biologically active silver from nanosilver surfaces. ACS Nano 4, 6903-6913 (2010)

38. Zhang, W., Yao, Y., Li, K., Huang, Y., Chen, Y.: Influence of dissolved oxygen on aggregation kinetics of citrate-coated silver nanoparticles. Environ. Pollut. 159, 3757-3762 (2011)

39. Ruparelia, J.P., Chatterjee, A.K., Duttagupta, S.P., Mukherji, S.: Strain specificity in antimicrobial activity of silver and copper nanoparticles. Acta Biomater. 4, 707-716 (2008) 